See discussions, stats, and author profiles for this publication at: https://www.researchgate.net/publication/275209512

\title{
Political Space Representations with Approval Data
}

Article in Electoral Studies · April 2015

DOI: 10.1016/j.electstud.2015.04.003

CITATIONS

2

2 authors:

8

Carlos Alós-Ferrer

University of Zurich

106 PUBLICATIONS 1,103 CITATIONS

SEE PROFILE
READS

162

(2) Georg D. Granic

14 PUBLICATIONS 38 CITATIONS

SEE PROFILE 


\title{
Political Space Representations with Approval Data
}

\author{
Carlos Alós-Ferrer * and Đura-Georg Granić ${ }^{\dagger}$
}

\begin{abstract}
Data from political elections provide a snapshot of the political landscape of a country or region. This snapshot is filtered, and maybe also distorted, through the lens of the voting method in place. The standard Plurality Voting method, by virtue of asking every voter to report only the maximum of his or her preferences, might provide too little data for an accurate snapshot. We analyze data from two large-scale field experiments in Germany, where voters employed Approval Voting for both parties and candidates. The analysis reveals that the underlying political landscapes, as perceived by the voters, are inherently multidimensional and cannot be reduced to a single left-right dimension, or even to a two-dimensional space. We compare the obtained representations with those derived from party positions as revealed by the 'Wahl-o-Mat' voting advice application, and further compare the results with those of the W-Nominate procedure.
\end{abstract}

Keywords: political space, policy positions, approval voting, W-Nominate

Working Paper. This is an author-generated version of a research manuscript which is currently under evaluation at a journal. It is circulated exclusively for the purpose of facilitating scientific discussion. The final version of the article might differ from this one.

*University of Cologne, Department of Economics. Albertus-Magnus Platz, D-50923 Cologne (Germany). Phone: (0049) 221470 8303. Fax: (0049) 2214708321 . E-mail: carlos.alosferrer@uni-koeln.de

$\dagger$ University of Cologne, Department of Economics. Albertus-Magnus Platz, D-50923 Cologne (Germany). E-mail: georg.granic@uni-koeln.de 


\section{Introduction}

The results of a given political election provide more than a mere ranking of the alternatives (be them parties or candidates). They offer a detailed picture of the political opinion of a country, state, or community, which can be taken as a snapshot of the opinion landscape of a democratic society at a specific point in time. This picture is, however, filtered by the voting method in use. It is well known that, for exactly the same electorate, different voting methods might well produce different results (see e.g. Saari, 1994). Voting methods also differ in the kind and amount of additional information that political science researchers might obtain from them, and how accurate and detailed the produced snapshots are. When considering the merits of different voting methods, this informational aspect is not usually taken into consideration.

Before turning to the differences in methods, let us consider the snapshots first. In spatial models of party or candidate competition, policies or platforms are represented geometrically as points in a $k$-dimensional Euclidean space, $k \in \mathbb{N}$, the 'political space'. Its dimensions correspond to the different issues the electorate consider important. Each voter is assumed to have a most preferred policy or ideal point within this space. A voter's utility for a policy declines with the distance of the policy from his or her ideal point (see Davis et al., 1970; McKelvey, 1976; Enelow and Hinich, 1990).

How many issues or dimensions should be employed? In a further simplifying step, theoretical models often concentrate on a single, left-right dimension. For instance, Harrington and Hess (1996) investigate a two-candidate, unidimensional policy space model in which a candidate can influence voters' perceptions of her own ideology and the opponent's perceived ideology (positive and negative campaigning). In a similar setting, Bernhardt et al. (2009) show that if parties do not know voters' preferences precisely, voters ex ante strictly prefer symmetrically differentiated platforms over platform convergence at the median. The analysis in these and many other papers rests on the assumption of unidimensionality.

Given the theoretical and descriptive relevance of such models, estimating the positions of candidates/parties and the dimensionality of the political space have become important empirical tasks in political science. Different approaches exist, including mass surveys of voters (e.g. van der Brug and van Spanje, 2009), analysis of roll call data, i.e the recorded votes of deliberative bodies by means of nominate scores (e.g. Poole and Rosenthal, 1985, 1991; Jenkins, 1999; Londregan, 1999), analysis of hand-coded content of party manifestos (e.g. Budge et al., 2001) and expert surveys of country specialists (e.g. Benoit and Laver, 2007). A notable example is Wiesehomeier and Benoit (2009), who estimated the policy positions of parties and presidents of 18 Latin American countries based on expert surveys. Experts provided numerical estimates (on a scale from 1 to 20, where lower points represent typical left and higher numbers represent typical right positions) on up to 11 exogenously predetermined primary dimensions of policy as well as on a general left-right dimension for both parties and presidents. Factor analysis revealed that political contestation can be reduced primarily to a single dimension composed of (as indicated by factor loadings) classical issues that distinguish 'left' from 'right' positions; more specifically, the main dimension explains up to $44 \%$ of the variance. This particular study could be taken as evidence that, although political spaces are multi-dimensional, a onedimensional approach might still be often admissible.

Suppose, however, that we concentrate on data originating from voters, rather than experts. Hence, we are aiming to estimate the political landscape as it is perceived by the agents who will ultimately take the relevant voting decisions. This might of course differ from the actual policy positions, but it is easy to argue that this space is highly relevant for political analysis. Further, as we will discuss below, this approach has the advantage that the number of dimensions to be used in the representation is endogenous, determined by the data, and not exogenously fixed.

Voter data is invariably generated according to variants of 'one man, one vote' systems, the 
most applied voting systems in contemporary democracies. These systems (including Plurality Voting) share the basic feature that voters are asked to provide a minimal quantity of information, namely the name of a candidate and/or the name of a party. Even with the entire set of cast ballots, the information we receive is of limited use for further analysis. In contrast, methods that ask voters to provide a full ranking of the alternatives or that allow voters to cast votes for more than one alternative, such as the Borda Count (see e.g. Saari, 1994) or Approval Voting (Brams and Fishburn, 1978; Laslier and Sanver, 2010), offer a richer picture of the political landscape.

We consider the latter method. Under Approval Voting, each voter is allowed to vote for (or "approve of") as many candidates as wished. This method has been defended on both theoretical (see Fishburn, 1978a,b; Alós-Ferrer, 2006) and empirical grounds (see Brams and Fishburn, 2005). Its proponents argue that it provides a more accurate reflection of voter wishes by virtue of collecting more information from voters in an easy-to-understand way. Further, voters lack incentives to misrepresent their preferences. For instance, the "wasted vote effect" disappears: even if a small party has little perceived chances of winning the election, its supporters can still approve of it without losing the possibility to approve of other parties. Additionally, Approval Voting is more likely to lead to a consensus vote, reducing both electorate polarization and the risk of 'smear campaigns', because the candidates depend on voters who also support other political parties. Due to these properties, Approval Voting has been adopted by a large number of scientific and professional associations across the world, as e.g. the Econometric Society, the Game Theory Society, and the Social Choice and Welfare Society.

For our purposes, the key advantage of approval data is that we can identify similarities between the available alternatives simply by counting the different constellations of parties or candidates voters approved of simultaneously, which is impossible under Plurality Voting. Based on this observation, Laslier (2006) developed the theory of Spatial Approval Voting. This article showed that, in the context of a probabilistic theory of voting, ${ }^{1}$ the information structure of the Approval Voting ballots suffices for a spatial representation of the parties and candidates. That is, the locations of the parties and candidates in the 'political' space are solely and endogenously determined by the correlations that we observe from the Approval Voting ballots.

All theoretical developments, however, remain of little use without an actual data set. Although no political elections are currently run under Approval Voting, a close substitute exists. Recently, a number of empirical studies have tested the performance of Approval Voting in the field, by conducting large-scale field experiments during actual elections, i.e. installing parallel booths where voters were able to cast a second, hypothetical vote according to the Approval Voting method. The first such experiments took place during the French Presidential Elections in 2002 (Laslier and Van der Straeten, 2008) and 2007 (Baujard and Igersheim, 2010), followed by two experiments in Germany during the 2008 State Elections in Hesse and the 2009 Federal Elections (Alós-Ferrer and Granić, 2010, 2012). The lessons learned from these experiments are varied. The bottom line, however, is that Approval Voting seems to deliver a more accurate snapshot of the voters' preferences than currently employed methods.

The present article undertakes two tasks. First, we estimate actual political landscapes using approval data from the 2008 and 2009 field experiments conducted by Alós-Ferrer and Granić (2010, 2012). Due to the particularities of the German electoral system, each election included a vote for parties and a separate vote for local candidates. Hence, the data set includes four elections taking place against a very similar political backdrop. Using the model in Laslier (2006), we obtain low-dimensional representations of the involved political landscapes. The question on the back of our minds was, "how low-dimensional can we go". Our analysis of

\footnotetext{
${ }^{1}$ To be more precise, if a random utility model (see e.g. Anderson et al., 1992) is applied to the spatial theory of voting.
} 
the data generated by these experimental elections under Approval Voting, however, point towards a relatively high dimensionality of the political space. The multidimensionality of these snapshots could not be obtained under methods such as Plurality Voting, which delivers too little information.

The second task we undertake is to obtain comparable political landscapes based on partyprovided data. To this end, we follow a relatively new approach (e.g. Tangian, 2013) and analyze the responses provided by parties to the German online voting advice application "Wahl-O-Mat". We show that this kind of data can be analyzed using the same estimation technique of Spatial Approval Voting. This accomplishes two objectives. First, we obtain a data set which can be analyzed simultaneously with Spatial Approval Voting and the well-established W-NOMINATE scaling procedure (Poole and Rosenthal, 1985, 1991; Poole et al., 2011). A comparison of the two resulting representations allows us to cross-validate our findings. Second, this kind of party-generated, issue-based data allows for a comparison of the estimation results with the existing (theoretical) literature on German party politics, hence enabling us to identify the main cleavages that we would expect to observe from the point of view of the running parties. In turn, the comparison with the representation obtained from approval data allows us to identify to which extent the judgments of the voters meet these predictions.

In line with previous findings, we identify two main dimensions of contestation in Germany when analyzing Wahl-O-Mat data, i.e. party-revealed positions (see e.g. Kriesi et al., 2006; Linhart and Shikano, 2009). This finding is robust in the changes of the estimation technique and is obtained under both Spatial Approval Voting and W-NOMINATE. Nonetheless, we identify important differences between the representations based on voting data and partyrevealed positions. We conclude that voters are more likely to be driven by political traditions than by actual political profiles of the parties and are more likely to overvalue 'wedge' issues stressed by smaller parties.

Previous research on public opinion established that structuring citizens' opinions requires more than one dimension (e.g. Kitschelt and McGann, 1995; Kriesi et al., 2008; van der Brug and van Spanje, 2009). However, many studies show that party choice is often driven by a single, left-right dimension (e.g., Oppenhuis, 1995; Van der Eijk et al., 1999). The argument reconciling these two observations is that, when casting a vote for a party, even voters who care about a number of political issues might be constrained to choose the closest party on the leftright spectrum (Sartori, 1976). However, the validity of this argument might crucially depend on the electoral system in use. The multidimensionality of our representations originates from actual voter choices among parties under approval voting. Our analysis suggests that, if the true political space is multidimensional and cannot be fruitfully reduced to, say, a single leftright dimension, the voting method used to generate the data needs to provide a rich enough structure for the researcher to be able to observe the multidimensionality.

\section{The Data Set}

We rely on data collected in two large-scale field experiments in Germany (Alós-Ferrer and Granić, 2010, 2012), which (in cooperation with state and federal authorities) took place during actual elections. That is, participants were voters who had just cast their votes in an official election and were invited to cast their vote again according to the Approval Voting method. The method allows voters to vote for (or approve of) as many alternatives as wished. The alternative with the most approvals is declared the winner. Approval Voting can be easily reformulated in terms of a series of yes/no question, where voters independently evaluate each feasible alternative as acceptable (approved of) or not, comparable to multidimensional roll call 
voting, where each dimension or issue represents a different alternative. ${ }^{2}$ Except for the method, the official election was mimicked as closely as possible, from setting up the experimental polling stations within the same buildings as the official polling stations, to listing the same alternatives in the same order as in the official election.

A particularity of German federal elections, and most of the state ones, is that voters are asked to cast two different votes. The first, for the district election, is given to a candidate, and the results are determined by the winner-takes-all procedure with simple majority. We will refer to this first vote as the "Constituency Vote". Half the seats in the parliaments are allocated through this method (direct seats). The second vote determines the percentage of the total seats (not the remaining ones) to be allocated to each different party which reaches at least $5 \%$ of the votes. We will refer to this second vote as the "List Vote". As a consequence, the data set contains data on four elections. In contrast to the French presidential election experiments in 2002 (Laslier and Van der Straeten, 2008) and 2007 (Baujard and Igersheim, 2010), two of the elections include approval data for parties. Indeed, this data set is the first instance where approval data for parties has been collected in a realistic voting situation.

The first experiment took place on January $27^{\text {th }} 2008$ during state elections in the German state of Hesse. These elections were expected to be very close. Indeed, it was not possible to form a government after the elections and new elections were called for. The experiment was carried out in the town of Messel, a small community in South Hesse containing three separate polling stations. From a total of 1909 personal voters who participated in the election, 967 $(50.65 \%)$ took part in the study.

The second experiment was carried out on September $27^{\text {th }} 2009$ during the nationwide German Federal elections in Konstanz, a city in the southern German state of Baden-Württemberg. As in Konstanz itself and most of Germany, the conservative party (CDU) was expected to receive a simple majority both for the district election and the party-list election (for a more detailed account, we refer the reader to Rohrschneider and Jung (2011) and the corresponding special symposium on this election). The study used a sample of 6 polling stations. In these stations, a total of 2879 personal voters took part in the official election; of those, 1431 (49.7\%) participated in the study.

By comparing the official results with the ones obtained in their experiments, Alós-Ferrer and Granić (2010, 2012) found that election results might have changed, sometimes dramatically, if Approval Voting rather than Plurality Voting had been used. Here, we will use the data with a different purpose: the computation of a political landscape snapshot using data which is simply unavailable under Plurality Voting.

\section{Spatial Approval Voting}

Let us briefly introduce the theoretical background of Spatial Approval Voting. A more detailed account is given in $\mathrm{A} .{ }^{3}$ We assume a political Euclidean space containing the locations of the candidates/parties and the voters' ideal points. The utility of a voter if an alternative is chosen is determined by the negative of the distance between the voter's ideal point and the alternative's location, plus a voter-independent valence term capturing the candidate's or party's idiosyncratic traits (e.g. charisma), and a random term. The distance is scaled by a parameter $\alpha$, which captures the salience of policy or political programs. The larger $\alpha$ is, the more relevant are political-space locations for voters' utilities. This parameter is left unspecified

\footnotetext{
${ }^{2}$ This interpretation is closely related to the question format considered in item response theory developed in Psychometrics (see Van Schuur, 2003). See, however, Laslier (2006, footnote 6).

${ }^{3}$ Including a minor correction made necessary by a misprinted formula in Laslier (2006).
} 
by the model. ${ }^{4}$

The probability that a voter approves of an alternative follows a random utility model, i.e. is determined by the distribution of the random term and a given utility threshold (see e.g. Anderson et al., 1992). The model also delivers estimates for the probability that a voter simultaneously approves of two different alternatives. On the other hand, experimental data delivers the number of approvals for each individual alternative, and also the number of simultaneous approvals of any two specific alternatives. The latter is referred to as the number of associations between two candidates. The resulting matrix of simultaneous approvals for all pairs of alternatives is called the association matrix. Under specific assumptions on the distribution of voters' ideal points in the political space, Laslier (2006) develops approximations for the number of approvals that a candidate receives and for the number of associations for any given pair of alternatives. Those are functions of $\alpha$ and the distances among the alternatives' positions in the political space. The formulae can be inverted to provide estimates of the distances as functions of the number of approvals and associations, which are actual outcomes in an approval election. Since the relation depends on $\alpha$, obtaining positive distances delivers a constraint (a lower bound) on $\alpha$.

In summary, experimental data from approval voting, and especially the numbers of associations, can be used to provide an estimate of political distances between candidates or parties, as perceived by voters. The next step for obtaining a representation is, given those distances, to use standard techniques from multidimensional scaling (see e.g. Seber, 1984) and principal component analysis (see e.g. Jolliffe, 2002) in order to actually obtain a spatial representation. From this representation, lower-dimensional projections can be considered which help with the visualization of the political space as resulting from an aggregation of voters' preferences. To assess the quality of the lower-dimensional representations, one uses the concept of explained inertia, which is defined as follows. Let the inertia $I$ of the set of alternatives be the sum of the square distances among all possible pairs. Let $I^{E}$ the the inertia of the projections of the alternatives in a lower-dimensional subspace $E$. The key component of the analysis is to check how much inertia is explained by lower-dimensional projections. For example, Laslier (2006) considers projections with roughly $70 \%$ explained inertia as a good fit and we will follow this practice. $^{5}$

\subsection{Data: Party Vote}

We now turn to the spatial representations derived from the data. A discussion of the involved difficulties and the accuracy of the representations for single parties is provided in B. An important constraint of the spatial representation method is that the association matrix cannot contain zero entries. ${ }^{6}$ This constraint is unlikely to be satisfied in field experiments involving a reasonable number of voters whenever many small parties are available. In the experiment, it was satisfied for Candidate Vote in both Messel and Konstanz, but not for the Party Vote (in neither case). To tackle this problem, we decided to exclude some of the smaller parties and reduce the set of alternatives to a manageable level. Since the theory of spatial voting determines the distance between two alternatives solely on the basis of approvals received and the associations between those two alternatives, we can restrict our analysis to a subset of

\footnotetext{
${ }^{4}$ The valence dimension is a major difference between this model and the standard analysis of roll-call votes through nominate scores (see, e.g., Poole and Rosenthal, 1985, 1991). Candidates/parties located at the same place in the political space can obtain different results due to the valence effect.

${ }^{5}$ The innovative part of spatial approval voting is the behavioral model of the decision making process underlying approval voting. Once the model distances are calculated, standard estimation techniques (multidimensional scaling) are used to find a representation; for more details on the exact procedure for obtaining a spatial representation, see A.

${ }^{6}$ Else one obtains infinitely large distances. See Equation (3) in A.
} 
alternatives without loss of generality and still draw meaningful and consistent conclusions. The parties we analyze in Messel are: SPD (social-democratic), CDU (conservative), the Greens, FDP (market liberal), the Left (neo-communist), Animal Protection Party, the Family Party, and the two extreme-right parties REP (Republicans) and NPD.

The association matrix for the party vote in Messel (reported in the Supplementary Online Materials, SOM) is strictly positive, hence finding a spatial representation is, in principle, possible. The smallest distance among the considered parties is the one between the two extreme-right parties, NPD and REP. For that distance to be positive, we obtain the constraint (see A) $\alpha \geq 3.69$. Hence, we set $\alpha=3.69$ resulting in a seven-dimensional representation from which a reliable three-dimensional projection can be obtained for illustrative purposes (explained inertia 65\%).

Figure 1(a,b) shows the latter three-dimensional representation of the political space for the parties in Messel. In all figures, we include a hypothetical "Left-Right Line" (more properly, a piecewise linear curve) for better visual orientation. This line is constructed connecting the locations of the parties which are traditionally perceived as having a clear left-right orientation. It starts at the position of the Left (far-left party), continues to that of the Greens, connects this point with the position of the SPD, and further continues to the location of the FDP, the CDU, and the far-right NPD.

To a certain extent, the first axis in Figure 1(a,b) reflects the standard one-dimensional categorization of the parties into left and right (compare with the Left-Right Line). The extreme-right parties REP and NPD are located far right, the German Social Democratic Party (SPD), the Greens and the Left (neo-communist) party on the center left and the far left, the conservative party CDU and the liberal party FDP in between. The center of the first axis is covered by the issue-oriented Animal Protection Party and the Family Party. This left-right ordering of the parties does not stem from any distributional assumption, but is endogenously determined by measuring the overlap of the different electorates.

Examination of Figure 1(a,b), however, indicates that a reduction of the political space to one dimension only would be misleading. The set of parties' positions is far away from being on a line. There are marked party differences along the second and third axes. As it is often the case in multidimensional political space studies, the interpretation of these axes is not unambiguous. For the second axis, the upper part contains the extreme right parties, as well as the extreme left party, and is opposed to the liberal party FDP and conservative Party CDU. The former in general support a stronger state with broader competencies for the government and more intervention in the market system, while the latter prefer a liberal market system without intervention by the state. A possible interpretation of the second axis is thus that it reflects the different standpoints market liberalism vs. state intervention.

It should also be remarked that even the three-dimensional projection might induce some misinterpretation. For example, the position of the Family Party in the three-dimensional projection should not be trusted (see B). Examination of the full, seven-dimensional representation reveals that this is the party closest to the NPD and REP. One of the major topics of the Family Party is the strengthening of the family and the preservation of traditional family values. Apparently, voters who approved of parties from the right end of the political spectrum also cared for family policy issues, especially preserving traditional family values.

The representation also delivers other interesting insights. For instance, we observe a strong clustering of the major parties. The distances between the SPD, the Green Party and the Left are almost of the same magnitude, but much larger than the distances to any other party. The party closest to the conservative CDU is the liberal FDP and vice versa. However, the distance between the far-right NPD and the conservative CDU is only slightly larger than that between the CDU and FDP. Of all the major parties, the CDU exhibits the smallest distance towards the extreme right parties REP and NPD. 
This bimodal distribution of parties in the space reflecting the polarization of the electorate after acrimoniously fought election campaigns between the SPD and CDU for the Hessian state election in 2008. Mr. Koch, the party-leader of the Hessian CDU, stressed some popular rightwing topics during his election campaign. He was pleading, for instance, for stronger penalties for delinquent adolescence that have a strong migration background. ${ }^{7}$ The distance between the CDU and SPD, the parties who were in the federal government in Germany the day of the experiment (the so-called "grand coalition", Scarrow, 2011), is very large. In fact, the far-left party the Left and the market-liberal party FDP are closer together than the parties of the big coalition, in terms of overlapping electorate. Indeed, the CDU's election posters directly targeted the leaders of the SPD, the Greens and the Left while the SPD's and the Green's leftward movement saw them campaigning for a minimum wage (for an election report see Broughton, 2008).

Let us turn to the data from Konstanz (Federal elections). The threshold value for $\alpha$ such that all model distances are positive is equal to 3.72. We set $\alpha$ accordingly, allowing for a reliable nine-dimensional representation (see B). However, with three dimensions we only explain about $57 \%$ of the inertia. Appropriately representing some of the parties requires more than five dimensions. Nevertheless, the technique employed to obtain a spatial representation is such that taking into account an additional dimension does not affect the coordinates of the parties on the previously analyzed dimensions. When interpreting the political space, the conclusions based on the relative positions along a given dimension, as those given below, remain valid although a party might not be well represented. However, the distances between certain parties might not be accurately represented. Therefore, we will refer to the full set of dimensions (nine in the case of Konstanz) when interpreting distances between parties.

Again we reduce the set of parties to obtain a restricted but strictly positive association matrix (reported in the SOM). The parties we analyze in Konstanz are: SPD, CDU, the Greens, FDP, the Left, Animal Protection Party, ödp (Ecological Democratic Party, environmentalist), the Violet Party (which pursues a social order based on "self-awareness through individual spirituality"), the Pirate Party (issue-oriented, supports the preservation of current civil rights on the Internet), REP, and NPD.

Figure 1(c,d) shows the three-dimensional representation of the political space for parties in Konstanz (including a Left-Right Line generated as explained above). In contrast to the case of Messel, the interpretation of the first axis is not so clear. The ideologically-related parties NPD and REP exhibit again the smallest distance, being located farthest right on the first axis. Next to them, we find the Left and the Violet Party. It is hard to argue that participants approving both of extreme-left and extreme-right parties are ideologically motivated. One possible explanation for the closeness between the German extreme right-wingers and extreme leftist is preferences towards extreme parties or, to put it plainly, protest voters. The center is occupied by the Pirate Party and the ödp. The large parties are located at the left. Hence, it seems that the first axis distinguishes the large traditional parties from smaller and extreme parties. ${ }^{8}$ We still observe clustering as in the case of Messel. The CDU has the smallest distance with the FDP and vice versa, the SPD is closest to the Greens, reflecting traditional coalitions in Germany. The parties with the smallest distance to the Greens are the Animal Protection Party and the ödp, quite naturally as all three parties emphasize environmental issues, but they are closely followed by the SPD. All three distances are of comparable magnitude. As a last

\footnotetext{
${ }^{7}$ This strategy is not new. The election polls in 2003 forecast a dramatic decrease in terms of share for Mr. Koch and his party. He then started a fiercely debated and polarizing election campaign. Mr. Koch was criticized for exploiting the mechanism of election campaign and fueling hatred against foreigners. At the end, his party received an absolute majority of seats.

${ }^{8}$ We have to point out that the City of Konstanz was ruled by a Green major at the time of the experiment and that the Green Party there is much stronger than in the rest of Germany, so the Green Party fits into the picture of a more traditional party.
} 
comment, our analysis shows that the right-wing parties NPD and REP are much more different than a usual one-dimensional, left-right, representation would suggest. The Republicans are more accepted (and therefore much closer in the representation) amongst the conservative voters who approved of CDU and FDP than the NPD. On the other hand, the NPD is closer to parties which care about environmental issues, such as the Greens and the ödp, than to the REP. In summary, the representation seems to deliver interesting insights which were not immediately obvious before the experiment, but which are far from arbitrary. In our view, observations as these validate the possible value of spatial representation techniques based on approval voting data to provide an accurate snapshot of voter preferences.

\subsection{Data: Candidate Vote}

The snapshot we obtain from the candidate vote can potentially differ from the one of the party vote. First, the candidate election in the mixed-member proportional representation concerns the district level and is qualitatively different from the party election, which concerns the federal level. That is, the available candidates aspired to represent the local district level, while party votes where aggregated at the federal level. Second, during the analysis of the data, we encountered frequent cases of voters who approved of a particular candidate, but did not approve of the corresponding party, and vice versa. Voters may perceive a candidate as a worthwhile recipient of their approval, without agreeing with the general party position. ${ }^{9}$

The association matrix for the candidates in Messel (see the SOM) is strictly positive, hence we can represent the full set of candidates. A value of $\alpha=3.84$ allows for a six-dimensional representation and a three-dimensional projection thereof with an explained inertia of $73 \%$ (see B). The latter is shown in Figure 2(a,b), where again we include a Left-Right Line as a visual aid. The first axis distinguishes Left-wing and Right-wing candidates. The center of this axis is empty. Comparing the party and candidate representations, the candidate vote seems to be more polarized than the party vote. The far ends of the representation move closer together. Nevertheless, we observe the same pattern of clustering of the major candidates that we observed for parties. The SPD, the Left, and the Greens candidates form one cluster, the candidates of the CDU and the FDP another one. The SPD exhibits the smallest distance to the Greens and vice versa. The same is true for the candidates of CDU and FDP. Again, reducing the space to one dimension is misleading. The distance between the center-right candidate of the CDU and the center-left candidate of the SPD is larger than the distance between the far-left and far-right candidates of the Left and the NPD.

Again, the association matrix for the candidates in Konstanz (see the SOM) is strictly positive and enables us to represent the full set of candidates. A value of $\alpha=2.55$ allows for a four-dimensional representation of the model distances (see B). All parties are well represented in the lower-dimensional projection. In fact, with three dimensions we explain about $98 \%$ of the inertia. It is an striking result that the three-dimensional projection yields such an accurate picture of the overall distances. However, a reduction to only one dimension would explain only $54 \%$ of the inertia.

At first glance, the number of available candidates is much smaller than in the applications before. Yet, there is no obvious reason to assume that a smaller set of alternatives increases the precision of the lower-dimensional projections. The crucial point is that four dimensions are enough to find a good representation of the overall picture. Obviously, the more dimensions are required for an accurate representation, the poorer will be the lower-dimensional projections. Presumably, the particularities of the voting district Konstanz play an important role here.

The three-dimensional representation for the candidate vote in Konstanz is shown in Figure

\footnotetext{
${ }^{9}$ Of course, one can expect a high correlation between the evaluation of a party and that of its leader. See Wagner and Weßels (2011).
} 
$2(\mathrm{c}, \mathrm{d})$ (the far-right position in the Left-Right Line corresponds to the NPD candidate only, because there was no REP candidate in Konstanz). Similarly to our observations from the party vote representation, the first axis does not distinguish the left-wing from the right-wing candidates. The distance between the Left candidate and the right-wing candidate of the NPD is actually the smallest. Although the party vote and the candidate vote constitute two distinct idiosyncratic elections, we can transfer our findings for the representation from the former to latter. The overlap in the electorate for the two traditional coalitions can also be observed here with the further addition that the Left needs to be placed into the same cluster as the SPD and Greens as those parties exhibit a more or less equal distance to each other.

Again, examination of the representation reveals interesting insights on the local political landscape at the time of the election. For example, we already emphasized in the analysis for the Party Vote that the overlap of the electorate between the NPD and parties orientated towards environmental issues is similar to the overlap between the REP and conservative voters. This observation is even stronger for the Candidate Vote in the sense that the NPD candidate is located closer to the Green candidate than he is to the CDU candidate.

\section{A Method Comparison Using VAA Data}

The spatial representations in the last section revealed multi-dimensional political landscapes both for the state elections in 2008 in Hesse and the federal elections in 2009 in Germany. As with any other scaling method the theory of Spatial Approval Voting does not provide explicit meanings for the uncovered dimensions. The data input for this theory is a series of answers to yes/no questions measuring the electorate overlap for different parties without any reference to policies or positional issues.

The "theory-free" explorative approach implicit in all scaling methods constitutes both a merit and a demerit for the theory of Spatial Approval Voting. ${ }^{10}$ On the one hand, the dimensions are endogenously determined by the data, which means we do not need to worry about the omission of potentially relevant policy issues in a priori determined sets of survey questions, the aggregation of scores attached to positional issues across a particular set of experts, or even the possibly arguable category definitions for 'word scores' and manifesto analysis. On the other hand, each dimension may represent a mix of several underlying issues, conflicts and party cleavages which may not be fully revealed or identified. Furthermore, the obtained representations take into account the perspective of the voters only. It is thus important to contrast the results with a well-developed theory of party competition in Germany from the viewpoint of the "supply side", i.e. data arising from declared party positions.

To provide an answer to these questions and validate our analysis, we re-estimate the policy space using party signals as data inputs. Our aim is to compare the results with those obtained from our field experiments data, thereby comparing a content-based representation obtained from explicit party positions with our representation based on voter perceptions. ${ }^{11}$ Before that, however, we conduct a preliminary step. Since the theory of Spatial Approval Voting is a relatively new method and Approval Voting data sets within "real" political contexts are rare, we also cross-validate the new estimations by comparing them to W-NOMINATE (Poole and Rosenthal, 1985, 1991) ones. This scaling procedure is the natural method for cross-validation because responses under Approval Voting are similar to roll calls.

\footnotetext{
${ }^{10}$ The expression "theory-free" refers here to the underlying political space to be estimated and not to the estimation methods themselves, which of course come from well developed theories.

${ }^{11}$ We focus here on the Party Vote elections. The Candidate Vote receives far less attention and a lower media coverage due its local nature. Further, parliament members elected through the Candidate Vote can decide not to follow the general party line (see e.g. Sieberer, 2010). An analysis of the difference between constituency candidates and party lines is beyond the scope of the present article.
} 
The new representations based on party data can be directly compared with our Party Vote representations, and show that the latter stand on a solid base. We then revisit the existing literature on party competition in Germany embedding our findings into existing theories. This allows us identify the main dimensions of political contestation from the point of view of the competing parties.

\subsection{Wahl-O-Mat Estimation}

The data set we use to model the supply side, i.e. party positions as viewed by the parties themselves, are responses provided by the parties to the online voting advice application "WahlO-Mat" organized by the Federal Agency for Civic Education. Unfortunately, there is no WahlO-Mat data available for the Hessian election in 2008, hence we present here only the results for the federal election in 2009. ${ }^{12}$ The Wahl-O-Mat is a non-party service that confronts the end user with a series of propositions such as "There should be a quota for women in leading positions" and "Germany should leave the European Union". The user expresses his opinion on each of the propositions ("I agree", "Neutral" or "I disagree"). Extra options allow users to skip a proposition or attach extra weight to propositions they consider important. Before the launch of the Wahl-O-Mat site for a particular election, the running parties position themselves on all propositions. At the end of the process the Wahl-O-Mat displays the agreement scores between users and parties. We use the party signals, i.e. the responses of the parties provided to the online application, as inputs for the spatial representation. Since the site is publicly accessible, the responses can be regarded as the parties' sincere statements regarding each of the various propositions. Our translation of the 38 Wahl-O-Mat questions can be found in Appendix C. The detailed party responses can be found in the SOM.

The innovation in our approach is using this data as input for Spatial Approval Voting. The latter uses simultaneous approvals of parties by voters to determine the overlaps in the perception of parties by voters. Applying Spatial Approval to the voting advice application data, we propose to use the simultaneous approval of propositions by parties ("I agree" statements) to determine the overlaps in the programmatic positions of parties. To understand why this is feasible, one can think of the following reinterpretation of the data. Conceive of each proposition as a hypothetical voter who cares most about the issue captured by the proposition and then decides which parties to approve of, i.e. approves of all the parties which agree with the proposition. This allows us to build an association matrix which is directly comparable to the one we obtain from our Approval Voting field experiments. ${ }^{13}$

For validation purposes, we used the same data to conduct a parallel estimation using WNOMINATE. One can simply imagine that the parties form a deliberative body and vote over whether or not to adopt each proposition. The party responses then form a roll call matrix which can be used to implement the W-NOMINATE algorithm (Poole et al., 2011).

The spatial representations obtained from Wahl-O-Mat data through Spatial Approval Voting and W-NOMINATE are shown in Figure 3. Goodness-of-fit measures for the explanatory power of the different dimensions are reported in the SOM. The representations obtained from Spatial Approval Voting and W-NOMINATE agree to high degree on the relative positions of the parties on the first two dimensions. The correlation coefficients (Pearson) for party positions between the two models are 0.94 and 0.96 for the first and second dimensions, respectively. Moreover, the political competition, independently of the scaling method used, is essentially

\footnotetext{
${ }^{12}$ The party inputs for the'Wahl-O-Mat were used in Tangian (2013) to analyze the federal election in Germany in 2009 from the viewpoint of direct democracy. For a detailed description of the Wahl-O-Mat see Marschall and Schmidt (2010). A more general discussion on voting advice applications is provided in the special symposium on the very same topic forthcoming in Electoral Studies, see Rosema et al. (forthcoming) and references therein.

${ }^{13} \mathrm{~A}$ different way to compute the association matrix is to count how often pairs of parties agree in their statements on the propositions. The corresponding analysis yields qualitatively similar results.
} 
two-dimensional. The first two dimensions explain $77 \%$ of the variance under Spatial Approval Voting. Similarly, under the W-NOMINATE procedure, with two dimensions we obtain $91.85 \%$ correct classifications with an Aggregate Proportional Reduction Error (APRE) of 0.72. ${ }^{14}$

This analysis illustrates that Spatial Approval Voting estimates are similar to W-NOMINATE ones when both can be applied to the same data set. However, we remark that it is in general not possible to apply W-NOMINATE to data sets where Spatial Approval Voting will generate representations. For instance, the W-NOMINATE algorithm cannot be directly applied to our Approval Voting field data. The reason is that Approval Voting data sets are highly skewed with roughly $85 \%$ responses corresponding to non-approvals. The relatively small number of parties (or roll-calls if interpreted in terms of W-NOMINATE) in comparison to voters as well as the fact that many parties receive approval rates smaller than $1.0 \%$ makes estimation infeasible.

\subsection{Comparison and Theoretical Background}

The finding that party positions in Germany, as obtained from Wahl-O-Mat data, can be viewed as essentially two-dimensional is in line with the existing literature on political space representations in Germany. Indeed, the German policy space has been associated with two dimensions in previous studies. Unfortunately the literature disagrees on the nature of these dimensions and how the German parties should be located on these dimensions (Benoit et al., 2009). For example, analyzing data from the Comparative Manifesto Project, Linhart and Shikano (2009) reject the notion of a left/right-wing super-issue in favor of a two-dimensional policy space for Germany (Economic and Social Policy dimensions). Analyzing contents of editorial sections of newspapers, Kriesi et al. (2006) identified an economic and a cultural dimension in contemporary Western Europe democracies including Germany. Moreover, these studies show ample evidence that parties change their issue positions over time.

In spite of the heterogeneous findings for the exact positioning of the parties, in view of the literature we can easily identify the important cleavages depicted in our Wahl-O-Mat data representations in Figure 3(a) and (b). The first dimension is the Socio-Economic dimension that separates the left, the greens and the socialist from the liberals, conservatives and Christian democrats. Not surprisingly, the extreme-right party NPD is associated with a more socialist type of Socio-Economic policy. For instance, the NPD supports nation-wide minimal wages, permanent equity holdings by the government in private banks, and governmental control over top-manager salaries. The second dimension is compatible with the findings in Kriesi et al. (2006) and broadly corresponds to the cultural dimension. Parties like the FDP and the Pirates fight for freedom in the net and against government regulations, support gender equality and equal rights for same-sex couples, the strengthening of civil liberties and direct democratic rights, and argue for structural reforms to increase efficiency and transparency of the government and public administration. On the other extreme of the cultural dimension, the NPD is the epitome of cultural demarcation. The party disapproves of the current German democratic order and constitution, and aspires to establish a tougher, authoritarian state. The party is homophobic, anti-EU and anti-NATO, and contends that Germany should be "cleansed" from foreign, capitalistic influences.

Figure 3(c) again presents the Party Vote representation from the 2009 federal election in Konstanz and is obtained by interchanging dimensions 1 and 2 and inverting dimension 1 from the original representation shown in Figure 1(c). A comparison of Figures 3(a) and 3(c) shows that circular structure in the first two dimensions is present both in party statements and from the point of view of the voters. The correlation analysis between the Wahl-O-Mat data and

\footnotetext{
${ }^{14}$ The two-dimensional interpretation of the W-NOMINATE results is also supported by the corresponding scree plot, the normalized eigenvalues fall off fairly smoothly after the 3rd value (see e.g. Poole, 2005, page 144-164, for a discussion of scree plots).
} 
the approval voting data confirms the existence of the Socio-Economic Dimension. Specifically, the correlation coefficient is 0.90 for this dimension, which is a high value especially if taking into account that the representations are based on fundamentally different data. Further, the labeling of the dimensions enabled by the comparative analysis yields a likely interpretation for the circular structure. This might be a manifestation of the financial crises and the struggle to overcome economic recession by the then-ruling grand coalition. Discontent voters were lead to endorse anti-incumbent alternatives from 'both ends' of the political spectrum (for an election report see Helms, 2010).

There are, however, major differences between the representations in Figures 3(a) and 3(c). First, we cannot identify the Cultural dimension. This has nothing to do with our choice of the two dimensions. Whichever combination of dimensions we consider from the Party Vote estimations, compared to the Wahl-O-Mat estimates the Pirate Party is bound to the center and the FDP is tied to the position of the CDU. This suggest that voters are more likely to be driven by political traditions than by actual political profiles of the parties and are more likely to overvalue 'wedge' issues stressed by smaller parties. While the Pirate Party offers opinions on many issues it is mainly perceived as defending the privacy and freedom of the net. This programmatic issue is actually supported by many voters throughout all political camps. The same is true, albeit to a lesser extent, for the Animal Protection Party and the ödp. Similarly, the FDP tied its fate the CDU by explicitly campaigning for a coalition with CDU and asking CDU voters to support the FDP with their Party Vote. Second, the SocioEconomic Dimension is no longer the most important dimension in terms of explanatory power. Crucially, the representations from the point of view of the voters suggest the existence of more than two dimensions for the political landscape in Germany.

Germany (Kriesi et al., 2006; Linhart and Shikano, 2009, e.g.) and in general Western European countries (e.g. Warwick, 2002) have been often associated with multi-dimensional contestation. The theme of multi-dimensionality has been established under many different estimation techniques including the NOMINATE algorithm. For example, Hix et al. (2006) identify an important second, albeit less salient dimension of politics in the European Parliament. In line with these findings our results suggest, from the point of view of the competing parties, a two-dimensional political contestation in Germany. Nonetheless, we identify important differences between supply side and demand side representations; in particular, the latter appears to require a larger number of dimensions. Notably, these differences arise using the same estimation technique and simply changing the input source. We conclude that voters are more likely to be driven by political traditions than by the actual political profiles of the parties.

The differences between representations based on party statements and those based on voter perceptions resonate with previous work in the literature. For instance, a discrepancy between representations obtained through different input sources has also been observed in van der Brug and van Spanje (2009). The interpretation of our results is also aligned with the findings in Rohrschneider and Whitefield (2009). Relying on an expert survey for 13 post-Communist democracies, these authors argue that the characteristics of political landscapes might often be blurred if the distinction between issue position and issue salience is not taken into account. In our opinion, issue salience will typically play a stronger role whenever actual voter data is considered, while party-originated data as that from voting advice applications (with an exogenous set of propositions) might offer a picture more centered on pure issue positions. This view fits well with our observations. The explanatory power of the Socio-Economic dimensions for our representations based on party signals is by far the largest one. However, voters attach a much lower salience to this issue, and other dimensions become equally or even more important. Further, voters seem to view wedge issues as more salient, and also attach a higher salience to non-programmatic aspects as e.g. traditional coalitions. 


\section{Conclusion}

This paper presents new evidence on the spatial representation of political landscapes using a unique data set which contains approval data for two party elections and two candidate elections in Germany. Our study is the first to estimate a political landscape for parties on the basis of such data. We use the data to obtain spatial representations of parties and candidates in an endogenously determined political space. This is made possible by techniques developed in Laslier (2006). This model delivers an interesting method for obtaining spatial representations of political positions, which uses data not available under e.g. Plurality Voting. The researcher observes the approval data in an experiment, uses these data to estimate the distances among parties, and finally obtains a low-dimensional spatial representation. The objective is to obtain an accurate representation with as low a dimensionality as possible. The dimensions, however, are endogenous and need not correspond to exogenously decided variables.

We compute spatial representations for all four elections, which in some cases are already reliable with a relatively low number of dimensions; one dimension, however, never suffices. This provides us with political snapshots of the electorate's preferences at the moment of the corresponding election. The representations also serve as efficient ways of organizing the data and illustrate how insights on the local political situation can be obtained. For instance, we observe a clustering of the traditional German coalitions among the large parties. The conservative CDU has the smallest distance with the liberal FDP and vice versa, and the social-democratic SPD is at a comparable distance to the Greens, reflecting traditional coalitions in Germany. The parties with the smallest distance toward the Greens also emphasize environmental issues. The radical right-wing NPD and Republican Party are not so close as one might expect, however. The Republicans are more accepted (and therefore much closer in the representation) amongst the conservative voters who approved of CDU and FDP than the NPD. On the other hand, the NPD is closer to environmental-issue parties than to the Republicans. In summary, the representations obtained from our data are politically sensible but also seem to deliver interesting insights which were not immediately obvious before the analysis of the data.

Our analysis has general consequences beyond the specific data set considered. Even though the method aims to obtain a representation with as few dimensions as possible, we still obtain representations with four dimensions or more. This is in sharp contrast to e.g. Wiesehomeier and Benoit (2009), who argue that their data can be structured along a single main left-right dimension. Our results, however, do not contradict that study at all. The two studies are at opposite extremes in several respects. First, Wiesehomeier and Benoit (2009) use expert data, while we rely on voting decisions cast by voters. Second, they start with exogenously given issues or dimensions which experts are asked about, while the dimensions in our approach are endogenously determined by the data. Third, they use data from central and south America, while ours originates in elections in Germany. It is fair to say that, taking both studies together, in some occasions and for some purposes assuming a single policy dimension might be a useful way to structure the data; but this remains an assumption which might be unwarranted in other situations and for other purposes.

The origin of the data is of particular importance. We also apply the representation method to party-generated data from the voting advice application "Wahl-O-Mat" and show that the results agree with those obtained when applying the W-NOMINATE algorithm to the same data. This serves two purposes. First, it offers a cross-validation of the method. Second, it allows us to contrast representations based on the demand side (voter perceptions) and on the supply side (party statements). Interestingly, the representations are generally in agreement but voter-based ones require a larger number of dimensions, reflecting the fact that, at least in the German case, voters' perceptions of parties include dimensions beyond those reflecting actual political profiles, as e.g. traditional coalitions or salient wedge issues. 
Finally, we want to emphasize that the analysis presented here illustrates how the use of approval data can present a definite advantage over election or poll data where voters only report their voting intention, i.e. a single party or candidate. It would be relatively easy to adapt polls to use an approach based on Approval Voting. If such a technology were adopted even in a fraction of studies, it could, in our opinion, represent a major advance for the spatial representation of political landscapes.

\section{Acknowledgments}

We thank Michael Bechtel, Steven Brams, and Jean-François Laslier for useful comments and suggestions. Granić gratefully acknowledges financial support from the German Research Foundation (DFG) through research project AL-1169/2-1 and through the research unit "Psychoeconomics" (FOR 1882).

\section{References}

Alós-Ferrer, C., 2006. A Simple Characterization of Approval Voting. Social Choice and Welfare $27,621-625$.

Alós-Ferrer, C., Granić, Đ.G., 2010. Approval Voting in Germany: Description of a Field Experiment, in: Laslier, J.F., Sanver, M.R. (Eds.), Handbook on Approval Voting. Springer.

Alós-Ferrer, C., Granić, Đ.G., 2012. Two Field Experiments on Approval Voting in Germany. Social Choice and Welfare 39, 171-205.

Anderson, S.P., de Palma, A., Thisse, J.F., 1992. Discrete Choice Theory of Product Differentiation. The MIT Press, Cambridge, MA.

Baujard, A., Igersheim, H., 2010. Framed Field Experiments on Approval Voting: Lessons from the 2002 and 2007 French Presidential Elections, in: Laslier, J.F., Sanver, M.R. (Eds.), Handbook on Approval Voting. Springer.

Benoit, K., Bräuninger, T., Debus, M., 2009. Challenges for estimating policy preferences: Announcing an open access archive of political documents. German Politics 18, 441-454.

Benoit, K., Laver, M., 2007. Estimating Party Policy Positions: Comparing Expert Surveys and Hand-Coded Content Analysis. Electoral Studies 26, 90-107.

Bernhardt, D., Duggan, J., Squintani, F., 2009. The Case for Responsible Parties. American Political Science Review 103, 570-587.

Brams, S.J., Fishburn, P.C., 1978. Approval Voting. The American Political Science Review $72,831-847$.

Brams, S.J., Fishburn, P.C., 2005. Going from Theory to Practice: The Mixed Success of Approval Voting. Social Choice and Welfare 25, 457-474.

Broughton, D., 2008. Frozen in the Centre, Melting at the Edges? The Landtagswahlen in Hesse and Lower Saxony, January 2008. German Politics 17, 203-211.

Budge, I., Klingemann, H.D., Volkens, A., Bara, J., Tanenbaum, E., 2001. Mapping Policy Preferences: Estimates for Parties, Electors, and Governments 1945-1988. Oxford: Oxford University Press. 
Davis, O.A., Hinich, M.J., Ordeshook, P.C., 1970. An Expository Development of a Mathematical Model of the Electoral Process. The American Political Science Review 64, 426-448.

Enelow, J.M., Hinich, M.J. (Eds.), 1990. Advances in the Spatial Theory of Voting. Camebridge: Cambridge University Press.

Fishburn, P.C., 1978a. Axioms for Approval Voting: Direct Proof. Journal of Economic Theory $19,180-185$.

Fishburn, P.C., 1978b. Symmetric and Consistent Aggregation with Dichotomous Voting, in: Laffont, J.J. (Ed.), Aggregation and Revelation of Preferences. North-Holland.

Harrington, J.E.J., Hess, G.D., 1996. A Spatial Theory of Positive and Negative Campaigning. Games and Economic Behavior 17, 209-229.

Helms, L., 2010. The German federal election, September 2009. Electoral Studies 29, 276-296.

Hix, S., Noury, A., Roland, G., 2006. Dimensions of Politics in the European Parliament. American Journal of Political Science 50, 494-511.

Jenkins, J.A., 1999. Examining the bonding effects of party: A comparative analysis of rollcall voting in the US and Confederate houses. American Journal of Political Science 43, 1144-1165.

Jolliffe, I.T., 2002. Principal Component Analysis. NY: Springer Verlag. $2^{\text {nd }}$ edition.

Kitschelt, H., McGann, A., 1995. The Radical Right in Western Europe: A Comparative Analysis. Ann Arbor, MI: University of Michigan Press.

Kriesi, H., Grande, E., Lachat, R., Dolezal, M., Bornschier, S., Frey, T., 2008. West European Politics in the Age of Globalization. Cambridge: Cambridge University Press.

Kriesi, H., Grande, E., Lachat, R., Dolezaland, M., Bornschier, S., Frey, T., 2006. Globalization and the Transformation of the National Political Space: Six European Countries Compared. European Journal of Political Research 45, 921-956.

Laslier, J.F., 1996. Multivariate description of comparison matrices. Journal of Multi-Criteria Decision Analysis 5, 112-126.

Laslier, J.F., 2006. Spatial Approval Voting. Political Analysis 14, 160-185.

Laslier, J.F., Sanver, M.R. (Eds.), 2010. Handbook on Approval Voting. Berlin Heidelberg: Springer Verlag.

Laslier, J.F., Van der Straeten, K., 2008. A Live Experiment on Approval Voting. Experimental Economics 11, 97-105.

Linhart, E., Shikano, S., 2009. Ideological Signals of German Parties in a Multi-Dimensional Space: An Estimation of Party Preferences Using the CMP Data. German Politics 18, 301-322.

Londregan, J.B., 1999. Estimating Legislators' Preferred Points. Political Analysis 8, 35-56.

Marschall, S., Schmidt, C.K., 2010. The Impact of Voting Indicators: The Case of the German Wahl-O-Mat, in: Cederoni, L., Garcia, D. (Eds.), Voting Advice Applications in Europe. The State of the Art. E-Book. 
McKelvey, R.D., 1976. Intransitivities in Multidimensional Voting Models and Some Implications for Agenda Control. Journal of Economic Theory 12, 472-482.

Oppenhuis, E., 1995. Voting Behavior in Europe: A Comparative Analysis of Electoral Participation and Party Choice. Amsterdam: Het Spinhuis.

Poole, K.T., 2005. Spatial Models of Parliamentary Voting. New York: Cambridge University Press.

Poole, K.T., Lewis, J., Lo, J., Carroll, R., 2011. Scaling Roll Call Votes with W-NOMINATE in R. Journal of Statistical Software 42, 1-21.

Poole, K.T., Rosenthal, H., 1985. A spatial model for legislative roll call analysis. American Journal of Political Science 29, 357-384.

Poole, K.T., Rosenthal, H., 1991. Patterns of congressional voting. American Journal of Political Science 35, 228-278.

Rohrschneider, R., Jung, F., 2011. SS: Germany's Federal Election in September 2009 - Elections in Times of Duress - Introduction. Electoral Studies 31, 1-4.

Rohrschneider, R., Whitefield, S., 2009. Understanding Cleavages in Party Systems: Issue Position and Issue Salience in 13 Post-Communist Democracies. Comparative Political Studies $42,280-313$.

Rosema, M., Anderson, J., Walgrave, S., forthcoming. The design, purpose, and effects of voting advice applications. Electoral Studies .

Saari, D.G., 1994. The Geometry of Voting. Berlin: Springer Verlag.

Sartori, G., 1976. Parties and Party Systems: A Framework for Analysis. Cambridge: Cambridge University Press.

Scarrow, S.E., 2011. The German Grand Coalition of 2005-09 and Party System Change: Catalyst or Continuity? Electoral Studies 31, 60-71.

Seber, G.A., 1984. Multivariate Observations. New York: Wiley.

Sieberer, U., 2010. Behavioral Consequences of Mixed Electoral Systems: Deviating Voting Behavior of District and List MPs in the German Bundestag. Electoral Studies 29, 484-496.

Tangian, A., 2013. German parliamentary Elections 2009 from the Viewpoint of Direct Democracy. Social Choice and Welfare 40, 833-869.

van der Brug, W., van Spanje, J., 2009. Immigration, Europe and the New Cultural Dimension. European Journal of Political Research 48, 309-334.

Van der Eijk, C., Franklin, M.N., Van der Brug, W., 1999. Policy Preferences and Party Choice, in: Schmitt, H., Thomassen, J. (Eds.), Political Representation and Legitimacy in the European Union. Oxford: Oxford University Press.

Van Schuur, W.H., 2003. Mokken Scale Analysis: A Nonparametric Version of Guttman Scaling for Survey Research. Political Analysis 11, 139-163.

Wagner, A., Weßels, B., 2011. Parties and Their Leaders. Does It Matter How They Match? The German General Elections 2009 in Comparison. Electoral Studies 31, 72-82. 
Warwick, P.V., 2002. Toward a Common Dimensionality in West European Policy Spaces. Party Politics 8, 101-122.

Wiesehomeier, N., Benoit, K., 2009. Presidents, Parties, and Policy Competition. The Journal of Politics 71, 1435-1447. 


\section{A Spatial Approval Voting: Theory}

In order to economize notation, and following Laslier (2006), we refer to the possible alternatives as "candidates". However, all statements apply for the case of parties.

The political space is a $k$-dimensional Euclidean space. There exists a set of voters $V$ of cardinality $N>0$ and a nonempty set of candidates $C$. Each candidate $c \in C$ is characterized by her location $y_{c} \in \mathbb{R}^{k}$, each voter $v \in V$ by her ideal point $x_{v} \in \mathbb{R}^{k}$. The distribution of the voters' ideal points has a density $f$.

The utility function of voter $v$ (over candidates) is given by:

$$
u_{v}(c)=-\alpha\left\|y_{c}-x_{v}\right\|^{2}+\Gamma_{c}+\epsilon_{v, c},
$$

where

- $\left\|y_{c}-x_{v}\right\|$ is the usual Euclidean distance between the candidate's location and the voter's ideal point and $\alpha$ is a policy salience parameter capturing the importance of political proximity for the voter's utility;

- $\Gamma_{c}=\log \left(\gamma_{c}\right)$ and $\gamma_{c}$ is a valence parameter, independent of the candidate $c$ 's location and voter $v$ 's identity, which captures the candidate's personal traits such as honesty, charisma, or competence; and

- $\epsilon_{v, c}$ is a disturbance term which is i.i.d. exponentially distributed with rate parameter 1 (i.e. the cumulative distribution function is given by: $F(\epsilon)=1-\exp (\epsilon)$ ).

Voting is probabilistic. A voter will approve of a candidate if (1) exceeds a certain fixed threshold, which can be normalized to zero without loss of generality. It follows that the probability that voter $v$ will approve of candidate $c$ (in the following denoted as the event $\left.A_{v c}=1\right)$ is given by

$$
\operatorname{Pr}\left[A_{v c}=1\right]=\operatorname{Pr}\left[\epsilon_{v, c} \geq \alpha\left\|y_{c}-x_{v}\right\|^{2}-\Gamma_{c}\right] .
$$

\section{Estimating Political Distances}

Given the distributional assumptions on $\epsilon_{v, c}$ from above, the approval probability can be written as

$$
\operatorname{Pr}\left[A_{v c}=1\right]=F\left(\alpha\left\|y_{c}-x_{v}\right\|^{2}-\Gamma_{c}\right)=\gamma_{c} \exp \left(-\alpha\left\|y_{c}-x_{v}\right\|^{2}\right) .
$$

A larger $\gamma_{c}$ implies a higher probability of approval, that is the higher the evaluation of the personal traits of a candidate, ceteris paribus, the larger is the probability that this candidate will be approved of. A large $\alpha$ implies a faster decrease in the probability when the distance between the candidate and the voter increases, that is, consideration about political locations play a stronger role in the decision whom to approve of when $\alpha$ is larger.

The random variables $A_{v, c}$ are independent, and hence the probability of voter $v$ approving of several candidates simultaneously is given by the product of the marginals.

The number of voters who approve of candidate $c$ follows from equation (2):

$$
a(c)=N \int \gamma_{c} \exp \left(-\alpha\left\|y_{c}-x\right\|^{2}\right) f(x) d x .
$$

Similarly, the number of voters who approve of candidates $c$ and $c^{\prime}$ simultaneously is

$$
a\left(c, c^{\prime}\right)=N \int \gamma_{c} \gamma_{c^{\prime}} \exp \left(-\alpha\left\|y_{c}-x\right\|^{2}-\alpha\left\|y_{c^{\prime}}-x\right\|^{2}\right) f(x) d x
$$


The number of approvals received by a candidate, $a(c)$, and the number of simultaneous approvals of two candidates, $a\left(c, c^{\prime}\right)$, are observable. Henceforth, $a\left(c, c^{\prime}\right)$ is referred to as the number of associations between two candidates. The remaining parameters of the model are $\alpha, \gamma_{c}$, the locations of the candidates $y_{c}$ and the density function $f$.

Under the hypothesis of a very flat distribution, it can be shown that experimental data provides us with enough information to determine the relative positions of candidates in the political space. To be more precise, let $f$ be the density of a normal distribution with concentration $\lambda$, centered around zero:

$$
f(x)=\left(\frac{\lambda}{\pi}\right)^{k / 2} \exp \left(-\lambda\|x\|^{2}\right) .
$$

If $\lambda$ tends to zero, we approach a uniform distribution of the ideal points in space. If $\lambda$ is small enough compared to $\alpha$, the formulae for the number of voters who approve of candidate $c$ and the number of associations between two candidates, can be approximated as follows.

$$
\begin{gathered}
a(c) \simeq N \gamma_{c}\left(\frac{\lambda}{\pi}\right)^{k / 2}, \\
a\left(c, c^{\prime}\right) \simeq N \gamma_{c} \gamma_{c^{\prime}}\left(\frac{\lambda}{\pi}\right)^{k / 2} \exp \left(-\frac{\alpha}{2}\left\|y_{c}-y_{c^{\prime}}\right\|^{2}\right) .
\end{gathered}
$$

As it can be seen from these expressions, the number of voters must be large enough, "precisely of the order of magnitude $N \simeq N_{0} \lambda^{-k / 2}$ " (Laslier, 2006), ${ }^{15}$ for the number of approvals not to degenerate, where $N_{0}$ is the actual number of participating voters. Standard manipulation shows that the distance between two candidates in the approximated model is given by

$$
\left\|y_{c}-y_{c^{\prime}}\right\|^{2} \simeq A^{\prime}-B^{\prime} \ln N_{0} \frac{a\left(c, c^{\prime}\right)}{a(c) a\left(c^{\prime}\right)}
$$

where $A^{\prime}=\frac{k}{\alpha} \ln \frac{\alpha}{2}$ and $B^{\prime}=\frac{2}{\alpha}$. Hence, the distance between two candidates no longer depends on their valence parameters. The quotient $a(c) a\left(c^{\prime}\right) / a\left(c, c^{\prime}\right)$ can be interpreted as a measure of correlation between the candidates. The more strongly the electorate of two candidates overlap, the smaller will be the distance between them.

\section{Obtaining the Spatial Representation}

The key for obtaining a spatial representation of the alternatives is Multidimensional Scaling and Principal Component Analysis. Let $y_{c}$ be $\mathrm{k}$ points in $\mathbb{R}^{k}$ centered at zero. A priori, one can assume $k$ to be equal to the number of available alternatives, since $k$ points in a Euclidean space of a higher dimension can always be embedded in $\mathbb{R}^{k}$. The inertia of $y=(y)_{c \in C}$ is defined as the sum of the squared distances,

$$
I(y)=\sum_{c, c^{\prime} \in C}\left\|y_{c}-y_{c^{\prime}}\right\|^{2}
$$

Let $y^{E}$ denote the projection of the system of points $y$ on a linear subspace $E$ of $\mathbb{R}^{k}$. $I\left(y^{E}\right)$ is the inertia explained by $E$ and the ratio $I\left(y^{E}\right) / I(y)$ measures the quality of the representation of $y$ by $y^{E}$. The goal is now to find a reliable (in terms of explained inertia) lower-dimensional representation of $y$.

\footnotetext{
${ }^{15}$ Unfortunately, this formula was misprinted in Laslier (2006). This is the corrected version.
} 
Let $D$ be the $(k \times k)$ symmetric distance matrix, i.e. $D_{12}$ is the distance between alternative 1 and 2 calculated according to (3). The representation is based on a matrix $\Gamma$ derived from $D$, called matrix of inertia, which is defined as

$$
\Gamma=(D \cdot J+J \cdot D-J \cdot D \cdot J-D) / 2
$$

where $J$ is a $(k \times k)$ matrix with all entries equal to 1 . Let $\mu_{1}, \ldots, \mu_{k}$ be the eigenvalues of $\Gamma$, ordered from largest to smallest, and let $\nu_{1}, \ldots, \nu_{k}$ be the corresponding normed eigenvectors. The best projection of the initial point system into a linear, $i$-dimensional subspace $E_{i}$ of $\mathbb{R}^{k}$ contains the center, $\sum_{c} y_{c}$, and is spanned by the first $i$ eigenvectors. Under the specifications above, the percentage of explained inertia in the $i$-dimensional representation is given by

$$
\rho(i)=\frac{I\left(y^{E_{i}}\right)}{I(y)}=\frac{\sum_{j=1}^{i} \mu_{j}}{\sum_{j=1}^{k} \mu_{j}} .
$$

The quality of representation for each single point can be measured by the cosine of the projection, which is given by

$$
r(c, i)=\frac{\left\|y^{E_{i}}\right\|}{\|y\|} .
$$

That is, the closer is $r(c, i)$ to 1 , the better is candidate $c$ represented.

As mentioned above, the model leaves unspecified the policy salience parameter $\alpha$. Estimated distance have to be non-negative anf this puts a lower bound on $\alpha$. We obtain the lower bound on $\alpha$ from Equation 3. For all pairwise comparisons of alternatives, it must be that ${ }^{16}$

$$
N_{0} \frac{a\left(c, c^{\prime}\right)}{a(c) a\left(c^{\prime}\right)} \leq\left(\frac{\alpha}{2}\right)^{k / 2} .
$$

\footnotetext{
${ }^{16}$ Due to the misprint mentioned previously, the version of this formula given in Laslier (2006) does not allow for a computation of the threshold for $\alpha$. This is the corrected version.
} 


\section{B Accuracy of the Spatial Representations}

The spatial representation relies on the eigenvectors and eigenvalues of the matrix of inertia given in (4), which is derived from the estimated distances. The positions of the parties along the first axis of the representation are given by $\sqrt{\mu_{1}} * \nu_{1}$, (see Laslier, 1996) where $\mu_{1}$ is the largest eigenvalue and $\nu_{1}$ is the corresponding eigenvector. Only the positive eigenvalues and their corresponding eigenvectors can be used for the spatial representation of the parties, in the sense that the dimensionality of the representation is constrained by the number of positive eigenvalues. The cosines of the projection computed according to (5) serve as a measure of the quality of the representation (detailed values are reported in the Supplementary Online Materials).

Party Vote, Messel. If $\alpha=3.69$, which is the (rounded) lower bound derived from (3) in order for all estimated distances to be positive, the first seven eigenvalues are real and positive. We can then explain about $65 \%$ of the inertia with a projection on three dimensions. ${ }^{17}$ The cosines of the projection indicate that most of the parties are well-represented (values from 0.737 to 0.995 with three dimensions). The only exception is the Family Party (value of 0.55), which would require more dimensions.

Party Vote, Konstanz. Equation (3) delivers a bound $\alpha \geq 3.72$ for all model distances to be positive. With $\alpha=3.72$, the first nine eigenvalues are real and positive. As mentioned in the text, with three dimensions we only explain about $57 \%$ of the inertia. ${ }^{18}$ The cosines of projection for the Greens (0.627 with three dimensions), the Pirate Party (0.422), and the Animal Protection Party (0.612) are rather low. Especially the Pirate Party and the Animal Protection Party require even more than four dimensions.

Candidate Vote, Messel. For all distances to be positive the policy salience parameter has to be larger than or equal to 3.84. With $\alpha=3.84$, the first six eigenvalues of the analysis are real and positive. With three dimensions, we explain about $69 \%$ of the inertia. ${ }^{19}$ Further, all eight candidates seem to be well-represented with only three dimensions, as indicated by the cosines of the projection (values from 0.758 to 0.968 ).

Candidate Vote, Konstanz. The threshold value for $\alpha$ such that all model distances are positive is equal to 2.55. With $\alpha=2.55$, the first four eigenvalues are real and positive. With three dimensions, we obtain an explained inertia of $98 \% .{ }^{20}$ All candidates are well-represented with only three dimensions, as indicated by the cosines of the projection (all values above $0.9796)$.

\footnotetext{
${ }^{17} 36.77 \%, 53.97 \%, 65.47 \%$, and $75.58 \%$ with one, two, three, and four dimensions, respectively. ${ }^{18} 24.23 \%, 45.08 \%, 57.42 \%$, and $66.78 \%$ with one, two, three, and four dimensions, respectively. ${ }^{19} 35.46 \%, 58.27 \%, 72.60 \%$, and $83.62 \%$ with one, two, three, and four dimensions, respectively.

${ }^{20} 53.97 \%, 91.36 \%, 98.34 \%$, and $100.00 \%$ with one, two, three, and four dimensions, respectively.
} 


\section{Wahl-O-Mat questionnaire items}

1. Prolong the life-span of nuclear power plants.

2. Introduce a nation-wide minimal wage.

3. Immediate withdrawal of German troops from Afghanistan.

4. Germany should leave the European Union.

5. No government control over top-manager salaries.

6. 6. Prohibit secret online surveillance of private computers.

7. The first university degree should be free of tuition fees.

8. Obligatory language test for all children of preschool age.

9. Unexceptionally ban of experiments on animals.

10. Equity holding of the government in private banks should to be temporary.

11. No trade relations with governments who violate human rights.

12. There should be a quota for women in leading positions.

13. Decrease corporate taxes.

14. Introduce referenda at the federal level.

15. Parents not using public daycare facilities should be compensated.

16. Guarantee an apprenticeship training position for every adolescent.

17. Relax protection against dismissals.

18. Turkey should be a full member of the European Union.

19. Introduce a general speed limit on German highways.

20. Financial aid (BAFOEG) for students and trainees regardless of parent income.

21. Reintroduce the Deutsche Mark (German pre-Euro currency).

22. More subsides for eco-farming.

23. German politics should follow Christian values.

24. Exclusive governmental ownership of railways.

25. Retain the compulsory military service.

26. Authorize production of genetically modified food.

27. Full adoption rights for homosexual couples.

28. Reintroduce a wealth tax.

29. Leave the education policy under the authority of the states. 
30. Less restriction on asylum policy.

31. Abolish quarterly fee for medical visits.

32. If wages decease, pensions can be reduced.

33. General export prohibition of military materials.

34. Maintain the 3-types of schooling system with different access to further education.

35. Municipal voting rights for foreign permanent residents.

36. Significantly increase unemployment benefits.

37. Allow domestic use of German military forces to fight terrorism.

38. The German democracy is the best form of government. 


\section{Figures}

(a) Messel, Dimensions 1 and 2

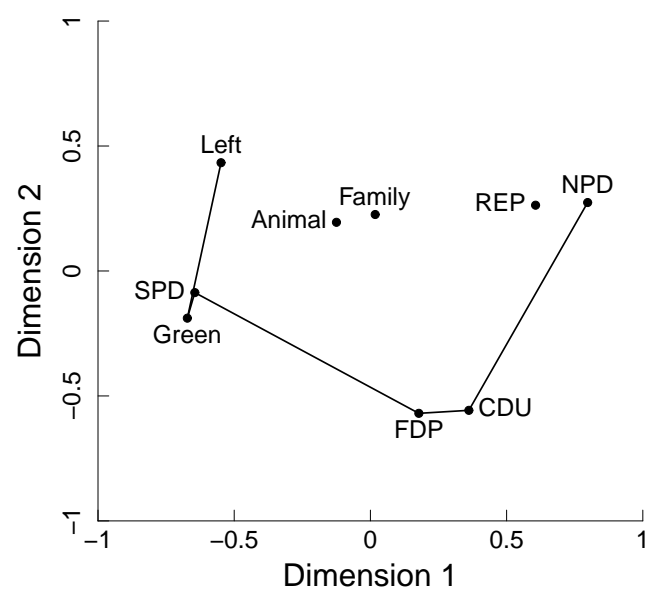

(c) Konstanz, Dimensions 1 and 2

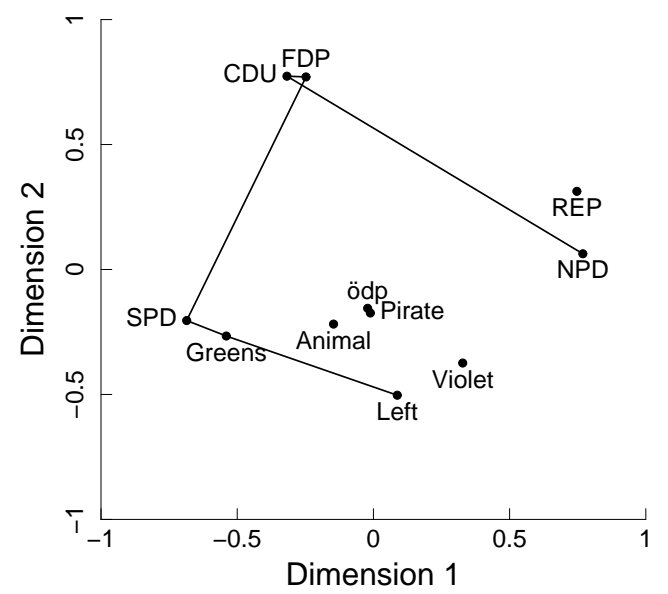

(b) Messel, Dimensions 1 and 3

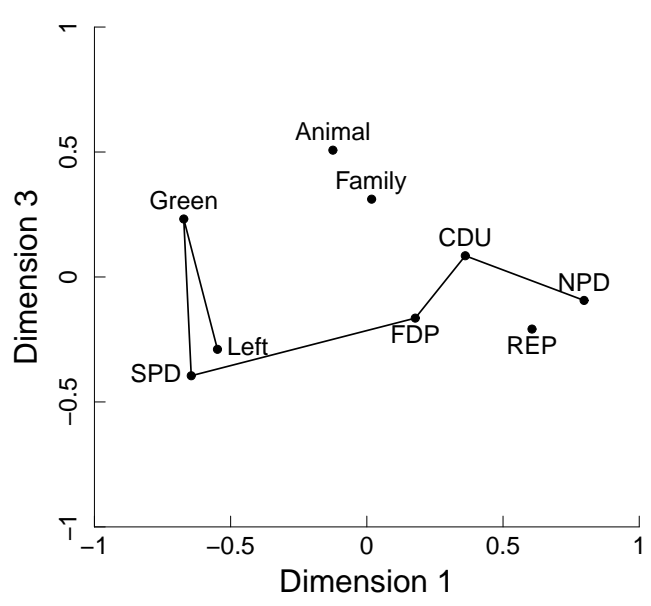

(d) Konstanz, Dimensions 1 and 3

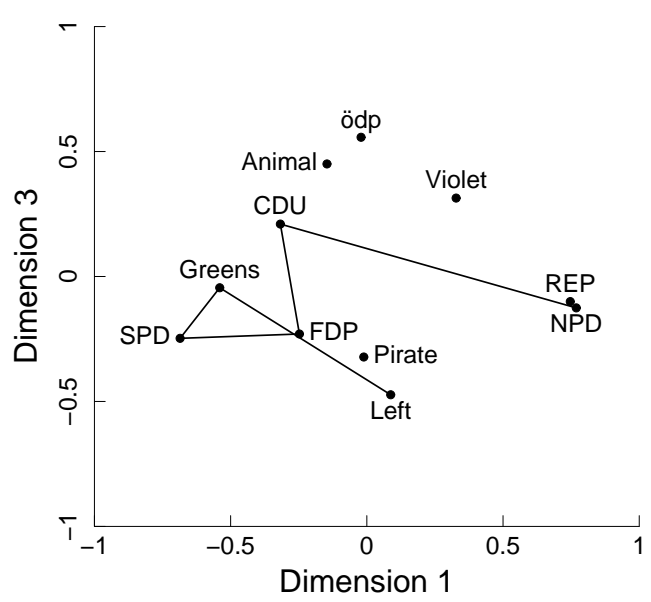

Figure 1: Spatial representations Party Vote. Sub-figures (a) and (b) show the threedimensional projection of the seven-dimensional party representation, Messel. Sub-figures (c) and (d) show the three-dimensional projection of the the nine-dimensional party representation, Konstanz. 
(a) Messel, Dimensions 1 and 2

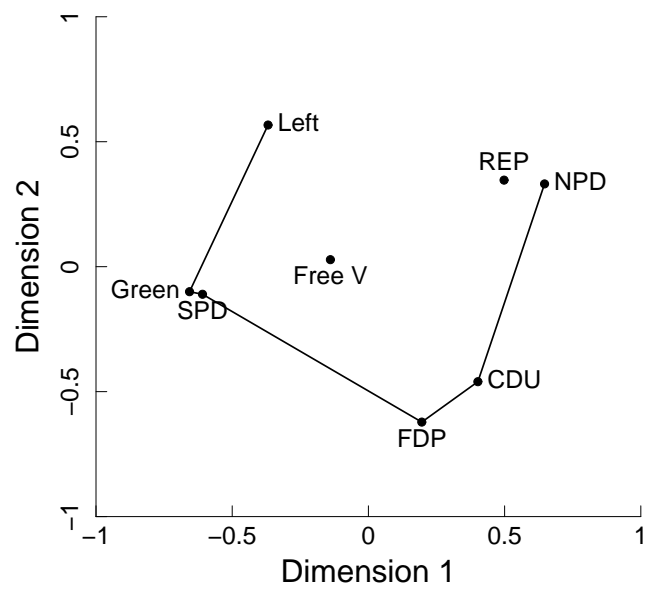

(c) Konstanz, Dimensions 1 and 2

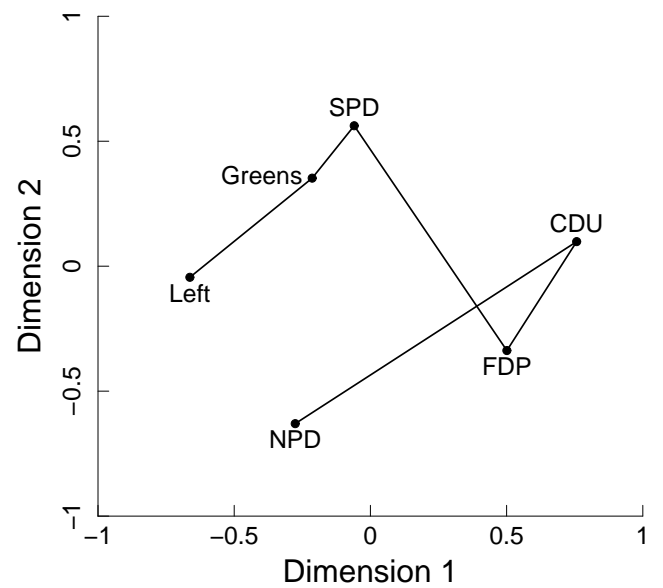

(b) Messel, Dimensions 1 and 3

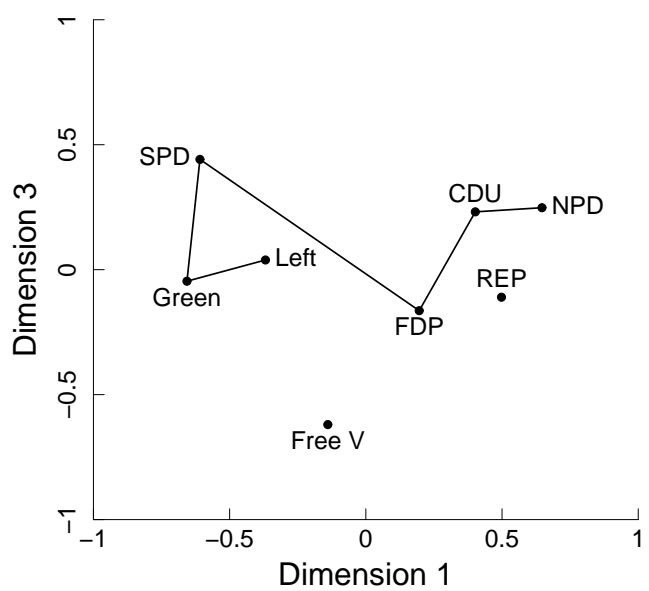

(d) Konstanz, Dimensions 1 and 3

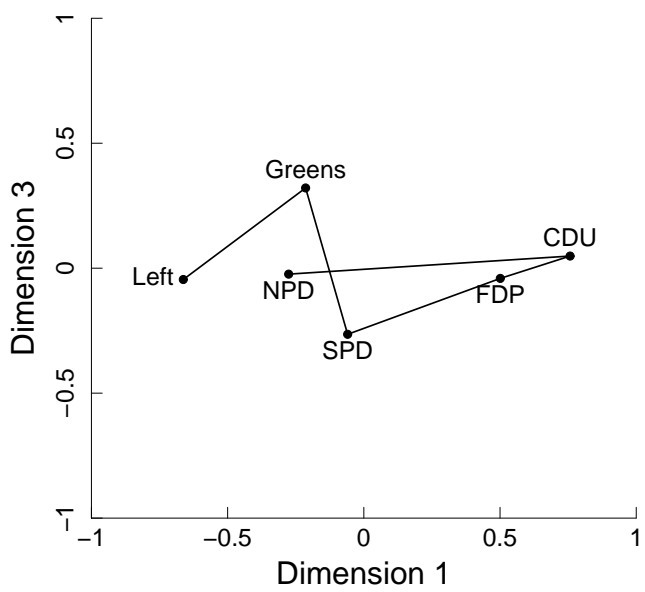

Figure 2: Spatial representations Candidate Vote. Sub-figures (a) and (b) show the threedimensional projection of the six-dimensional candidate representation, Messel. Sub-figures (c) and (d) show the three-dimensional projection of the four-dimensional candidate representation, Konstanz. 
(a) Spatial approval Voting

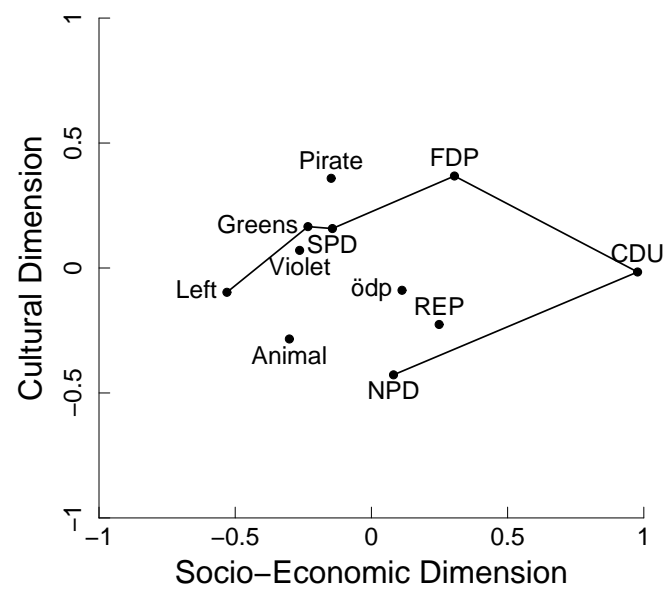

(b) W-NOMINATE

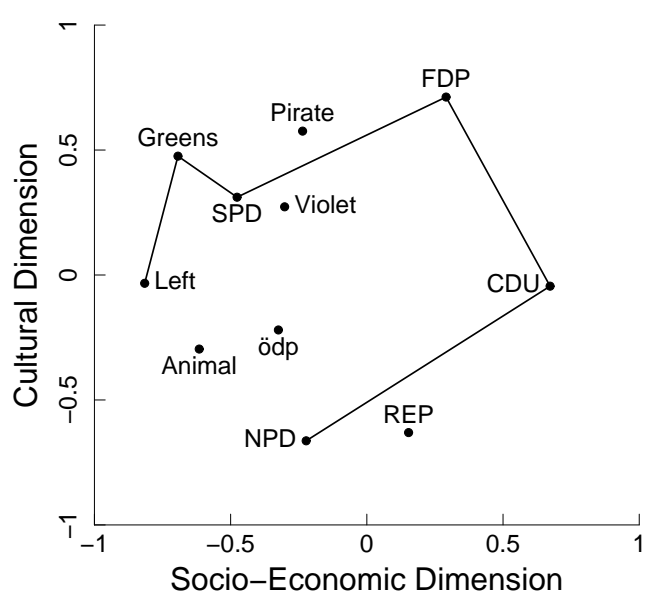

(c) Party Vote Konstanz

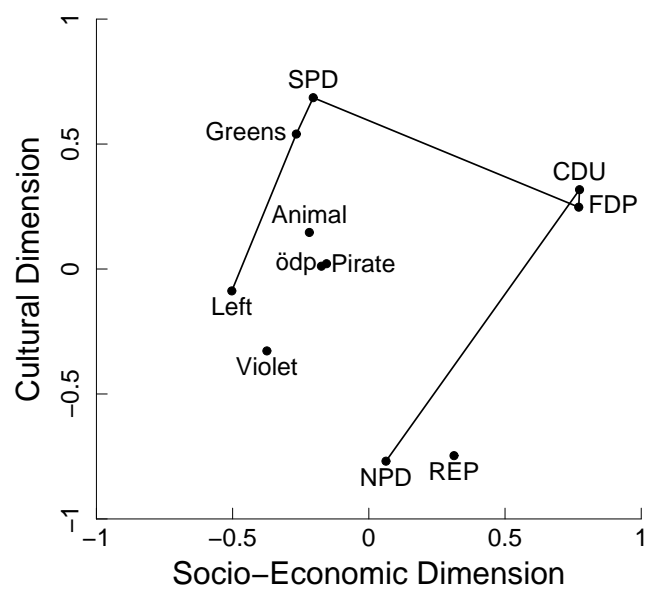

Figure 3: Spatial representations using the 2009 Wahl-O-Mat Data in sub-figures (a) and (b), and the Konstanz Party Vote in sub-figure (c). Spatial Approval Voting: Party $x$ and $y$ have one association if both explicitly approve of one item in the Wahlomat 2009 questionnaire. W-NOMINATE: Responses to the Wahl-O-Mat 2009 questionnaire items are treated as roll call data (Coding: I agree - Yay; I disagree - Nay; Neutral - Missing). Party Vote Konstanz: Socio-Economic Dimension - Dimension 2 of Figure 1 (c); Cultural Dimension - Inverse Dimension 1 of Figure 1 (c). 